\title{
Indications and imaging for aortic surgery: Size and other matters
}

\author{
John A. Elefteriades, MD, ${ }^{\text {a }}$ Bulat A. Ziganshin, MD, ${ }^{\text {a,b }}$ John A. Rizzo, PhD, ${ }^{\text {a,c }}$ Hai Fang, PhD, ${ }^{\mathrm{d}}$ \\ Maryann Tranquilli, RN, ${ }^{a}$ Vijayapraveena Paruchuri, MD, ${ }^{\mathrm{e}}$ Gregory Kuzmik, MD, ${ }^{\mathrm{a}}$ \\ George Gubernikoff, MD, ${ }^{\mathrm{e}}$ Julia Dumfarth, MD, ${ }^{\mathrm{a}}$ Paris Charilaou, MD, ${ }^{\mathrm{a}}$ and \\ Panagiotis Theodoropoulos, $\mathrm{MD}^{\mathrm{a}}$
}

\begin{abstract}
Objectives: To review the current general concepts and understanding of the natural history of thoracic aortic aneurysm and their clinical implications.

Methods: Data on the the normal thoracic aortas were derived from the database of the Multi-Ethnic Study of Atherosclerosis $(n=3573)$, representative of the general population. Data on diseased thoracic aorta were derived from the database of the Aortic Institute at Yale-New Haven Hospital $(n=3263)$, representative of patients with thoracic aortic aneurysm and dissection.
\end{abstract}

\begin{abstract}
Results: Our studies have shown that the normal aorta in the general population is small $(3.2 \mathrm{~cm}$ for the ascending aorta). Aortas larger than $5 \mathrm{~cm}$ are rare in the real world. The aneurysmal aorta grows at a mean of $0.2 \mathrm{~cm} / \mathrm{y}$, and larger aneurysms grow faster than do smaller ones. The dissection size paradox (which shows some aortic dissections occurring at small aneurysm sizes) is explained by the huge number of patients with small aortas in the general population. Genetic testing of patients with thoracic aortic disease helps identify genes responsible for aortic aneurysm and dissection. New imaging techniques such as 4-dimensional magnetic resonance imaging may add engineering data to our decision making.
\end{abstract}

Conclusions: Size continues to be a strong predictor of natural complications and a suitable parameter for intervention. As we enter the era of personalized aneurysm care, it is likely that specific genetic mutations will facilitate the determination of the appropriate size criterion for surgical intervention in individual cases. (J Thorac Cardiovasc Surg 2015;149:S10-3)

It has been a decade and a half since our original articles on the natural history of thoracic aortic aneurysm were written. ${ }^{1-5}$ Those articles were based on approximately 230 patients. Since that time, our database at the Aortic Institute at Yale-New Haven Hospital has grown dramatically.

For this presentation at the 2014 Aortic Symposium, we took the opportunity to revisit calculations regarding the natural history of thoracic aortic aneurysm, which are now based on subgroups among a total of 3263 patients. The study was approved by the institutional review board of Yale University, and the patients consented to

From the Aortic Institute at Yale-New Haven Hospital, ${ }^{a}$ Yale University School of Medicine, New Haven, Conn; the Department of Surgical Disease No. 2, ${ }^{\mathrm{b}}$ Kazan State Medical University, Kazan, Russia; the Departments of Economics and Preventive Medicine, ${ }^{\mathrm{c}}$ Stony Brook University, Stony Brook, NY; the China Center for Health Development Studies, ${ }^{\mathrm{d}}$ Peking University, Beijing, China; and the Department of Cardiology, ${ }^{\mathrm{e}}$ Winthrop University Hospital, Mineola, NY.

Disclosures: John A. Elefteriades reports consulting fees from Cryolife, Covidien, and Datascope and equity ownership in Coolspine. John A. Rizzo reports consulting fees from Clinical Trial and Consulting (CTI). All other authors have nothing to disclose with regard to commercial support.

Read at The American Association for Thoracic Surgery Aortic Symposium, New York, New York, April 24-25, 2014.

Received for publication May 1, 2014; revisions received July 17, 2014; accepted for publication July 25, 2014; available ahead of print Sept 11, 2014.

Address for reprints: John A. Elefteriades, MD, Aortic Institute at Yale-New Haven Hospital, Yale University School of Medicine, 789 Howard Ave, Clinic Building CB317, New Haven, CT 06510 (E-mail: john.elefteriades@yale.edu).

0022-5223/\$36.00

Copyright (c) 2015 by The American Association for Thoracic Surgery

http://dx.doi.org/10.1016/j.jtcvs.2014.07.066 participation. Findings that are based on such a large number of patients should carry enhanced statistical and clinical significance. These findings are reviewed here.

It is, of course, the natural history of a disease that underlies important therapeutic decisions. In the case of the thoracic aorta, it is precisely assessment of the natural history of aneurysmal disease that permits rational, evidencebased articulation of criteria for surgical intervention.

\section{HOW LARGE IS THE NORMAL AORTA?}

There is a relative paucity of data on the size of the normal aorta. This is understandable when one considers that normal, healthy people do not undergo echocardiography, computed tomography, or magnetic resonance imaging scans in the absence of symptoms or signs, or at least some suspicion, of clinical disease. Through the kindness of the Multi-Ethnic Study of Atherosclerosis (MESA) investigators, we were provided access to routine magnetic resonance imaging examinations of the thoracic aorta performed on 3573 individuals without clinical disease who were enrolled in a long-term, population-based study.

These data were tabulated and analyzed by our research team. The findings are presented in Figure 1. It can be seen that the distribution of aortic sizes approaches a normal distribution, albeit with a wider tail on the right side than on the left. The wider tail on the right side reflects the fact that the upper limit of aortic size can vary widely; on the other 


\section{Abbreviations and Acronyms \\ IRAD = International Registry of Aortic Dissection MESA $=$ Multi-Ethnic Study of Atherosclerosis}

hand, the tail is not wide on the left side of the curve because there is a lower limit to how small the aorta can be and still meet the body's needs.

Please note that the normal aorta is quite small, with an average dimension of only $3.2 \mathrm{~cm}$ (ascending aorta at the level of the right pulmonary artery). We in the aortic subspecialties come to have a skewed view of aortic size, simply because we see so many patients with dilated aortas. (The smallest aorta in the MESA series was $1.6 \mathrm{~cm}$, and the largest was $5.0 \mathrm{~cm}$.) Please note that there were no aortas larger than $5 \mathrm{~cm}$ in the MESA series of more than 3500 healthy individuals. Although at aortic centers we do not usually get excited until an aorta exceeds $5 \mathrm{~cm}$, such dimensions are distinctly unusual in the real world.

\section{HOW FAST DOES THE ANEURYSMAL AORTA GROW?}

The size distribution of the patients in our Yale Aortic Database is presented in Figure 2. We recognized some time ago that occasional patients with small aortas may sometimes have aortic dissections occur, as seen in this figure. (The patients entered in the lowest size ranges are there largely because of dissection, because they do not meet criteria for having an aneurysm.) The average aortic size of patients in our database was $4.71 \mathrm{~cm}$, and aortas on occasion exceeded $10 \mathrm{~cm}$. These aneurysmal aortas grew at $0.20,0.26$, and $0.23 \mathrm{~cm} / \mathrm{y}$ for the ascending aorta and arch, descending aorta, and thoracoabdominal aorta, respectively. Additionally, the larger the aortic aneurysm, the faster it grew, for all 3 categories (Figure 3). The descending aorta grew faster, statistically, than did the ascending aorta $(P=.011)$.

\section{HOW DOES AORTIC SIZE RELATE TO NATURAL COMPLICATIONS OF THORACIC AORTIC ANEURYSM?}

We had previously reported a close relationship between aortic size and the incidence of natural complications (rupture, dissection, and death). We were interested to see whether these relationships would still obtain in this much larger data sample.

The current analysis, with the much larger patient group, again demonstrates an escalating risk of rupture, dissection, or death as the aorta grows. For the ascending aorta, the yearly risks are $4.4 \%, 4.7 \%, 7.3 \%$, and $12.1 \%$ for aortic sizes of $4,5,6$, and $7 \mathrm{~cm}$, respectively. Corresponding "staircase" risk elevation with aortic size is also seen for descending and thoracoabdominal aortic aneurysms. Descending and thoracoabdominal aneurysms pose the highest risks.

These data provide strong additional evidence for the role of size in predicting the natural risk of thoracic aortic aneurysms and for the importance of size as an intervention criterion.

\section{WHAT ABOUT THE SIZE PARADOX FOR AORTIC DISSECTION?}

We have known from multiple studies ${ }^{1,3-5}$ that small aortas do not frequently dissect. However, Pape and colleagues $^{6}$ from the International Registry of Aortic Dissection (IRAD) presented an important study in which they reported that more than half of aortic dissections occurred with aortic diameters below the commonly accepted intervention criterion of $5.5 \mathrm{~cm}$. (We use $5 \mathrm{~cm}$ for our intervention criterion for the ascending aorta in healthy individuals because the operations can be performed safely, making a lower criterion point reasonable.)

Our own data have long demonstrated that some dissections occur at small sizes. Our most recent analysis, collected for this presentation, confirms that finding.

We were interested in what might explain this paradox. We suspected that this paradox might be related to the aortic size distribution characteristics in the general population. The IRAD study provides information only on the numerator, patients who have actually had an aortic dissection occur, but lacks information about the denominator, the number of patients at risk in each size distribution. In particular, we thought that the explanation for the paradox might lie in the shape of the tail of the aortic size distribution curve (Figure 4). ${ }^{7}$ The right tail of the curve gets "fatter" rapidly as one moves from the extreme tip of the curve toward the center of the frequency distribution. That is, a lot more patients fall into the smaller size groups than into the larger ones, so a lot more patients are at risk for aortic events. In other words, by knowing the number of patients in each size category in the population, one can put the IRAD data in perspective by getting a sense of the denominator of persons at risk, not only the numerator of patients with an aortic dissection.

With the MESA data presented previously, we were able to perform some calculations, comparing the number of dissections in each size range from IRAD with the number at risk in the general population from MESA. We recognize that these are different populations, but both the IRAD and the MESA data incorporate patients from multiple geographic and ethnic groups and have nearly identical mean ages.

This arithmetic shows that, although dissections do occasionally occur at small sizes, a patient with a larger aorta $(\geq 4.5 \mathrm{~cm})$ is an astounding 6.3 thousand times more likely to have an aortic dissection than is one with a small aorta $(\leq 3.4 \mathrm{~cm})$. 


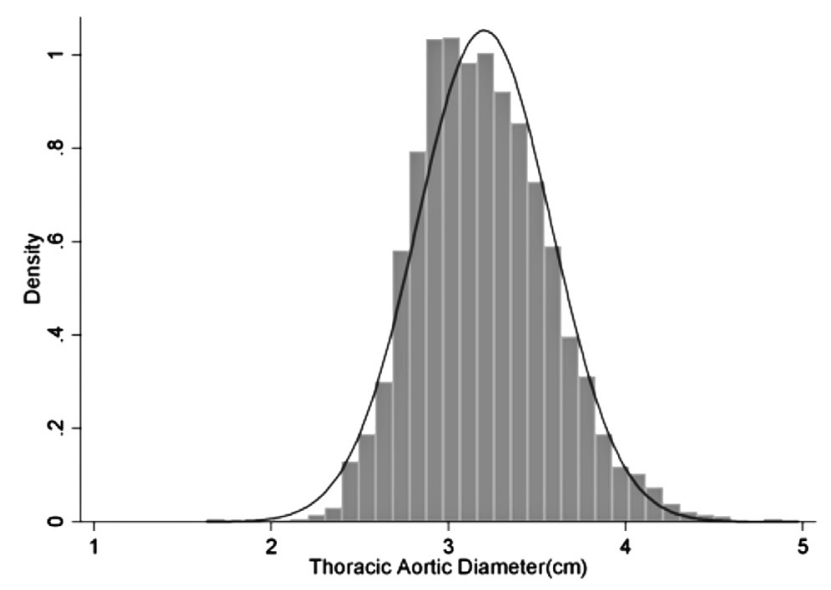

FIGURE 1. Population distribution of thoracic aortic diameter according to aortic root size (mean, $3.2 \mathrm{~cm}$ ).

Thus the size paradox for aortic dissection lies in the fact that there are hugely more patients at the smaller sizes, so that, despite the fact that dissection is vanishingly rare at these dimensions, such events are indeed frequent enough to be observed clinically. Wisely, the IRAD investigators did not recommend that their observations alter our intervention criteria in any way, and our MESA-empowered arithmetic analysis supports that posture.

\section{MOVING BEYOND SIZE: NEW DISSECTION GENES}

Size has proved to be, and continues to serve as, an excellent criterion for surgical intervention. Size is supported by the new data in this presentation.

Size is not, however, the entire story. Biology plays a critical role.

With the advent of rapid, affordable gene sequencing, a molecular genetic approach to aortic diseases is enhanced.

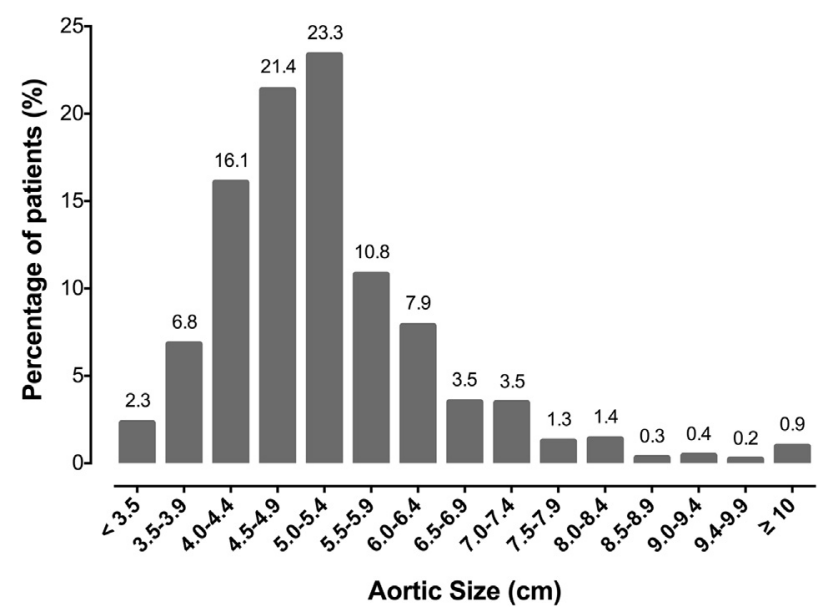

FIGURE 2. Distribution of patients at the Yale Aortic Institute according to aortic size.

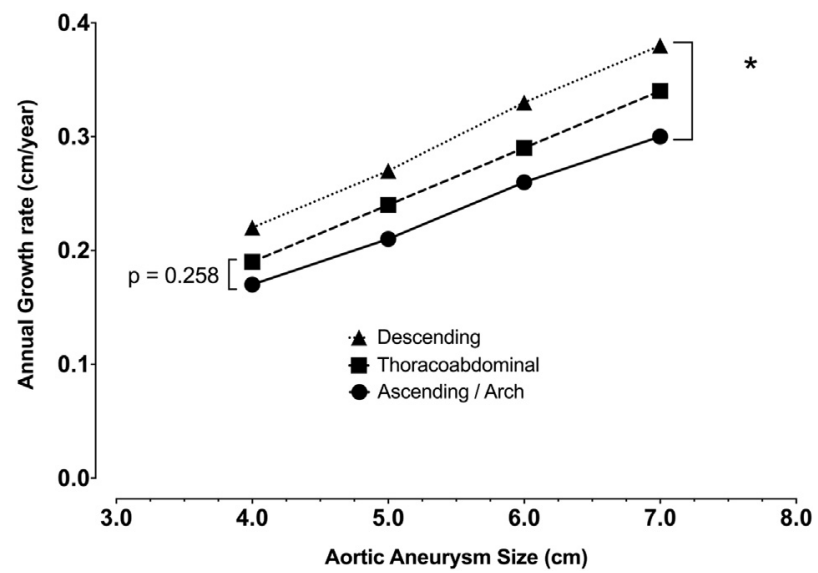

FIGURE 3. Rates of annual growth of the thoracic aorta. Asterisk indicates $P=.011$.

We have recently reviewed the current status of genetic screening for thoracic aortic aneurysm. ${ }^{8,9}$ There are now more than a dozen specific genetic mutations that may underlie thoracic aortic aneurysm and dissection. These mutations, however, "explain" only about $20 \%$ of thoracic aortic disease, with additional contributory mutations remaining to be discovered.

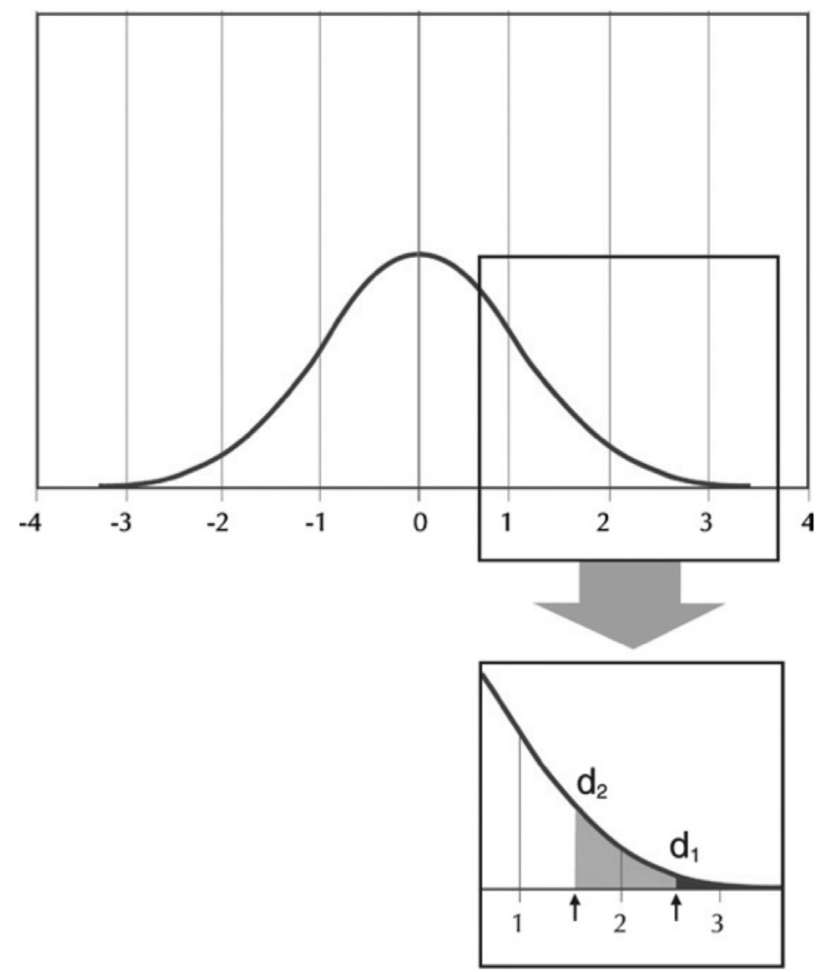

FIGURE 4. Theoretic normal distribution curve of aortic size. The huge general population at risk explains the occurrence of some dissections at small sizes (Reprinted with permission from Elefteriades JA, Farkas EA. Thoracic aortic aneurysm clinically pertinent controversies and uncertainties. J Am Coll Cardiol. 2010;55:841-57.7) 


\section{TABLE 1. Summary of important points}

- The normal aorta is small, with a mean diameter of $3.2 \mathrm{~cm}$ (ascending aorta at the level of the right pulmonary artery). Aortas larger in diameter than $5 \mathrm{~cm}$ are rare in the real world.

- The aneurysmal aorta grows at about $0.2 \mathrm{~cm} / \mathrm{y}$.

- The larger the aneurysm, the faster it grows.

- Size continues to be a strong predictor of natural complications and a suitable criterion for intervention.

- The dissection size paradox is explained by the huge number of patients with small aortas.

- KIF6 and FBN1 (rs2118181) are promising new "dissection genes" (KIF6 is clinically available).

- New imaging techniques (such as 4-dimensional magnetic resonance imaging) may add engineering data to our decision making.

Certain mutations predispose patients toward development of aortic dissection at small, even at times nonaneurysmal, dimensions. This is the case with Loeys-Dietz syndrome, with ACTA2 mutations, and with MYLK mutations. Identification of these mutations justifies very early, preemptive extirpation of the aorta to prevent dissection.

Also, two new "dissection genes," distinct from the syndromes just discussed, have been identified. Milewicz identified, and our group confirmed and extended, the finding that a base pair change at the rs2118181 locus on the FBN1 gene predisposes strongly (odds ratio, 1.87) toward the development of aortic dissection. ${ }^{10,11}$ This marker is not yet available, to our knowledge, as a clinical tool.

Our group (with our colleagues at Celera Genomics) has also identified a strong predisposition (odds ratio, 2.14-2.39) toward aortic dissection development in patients who carry a mutation in the KIF6 gene. There is a clinically available assay for this mutation because of its introduction as a marker of arteriosclerotic disease. We have begun to use positivity for the Arg allele in the KIF6 gene in our clinical decision making at our Aortic Institute.

\section{MOVING BEYOND SIZE: IMAGING WALL STRESS}

Our group, as well as many others, have focused on engineering analysis of the aortic wall, both in vivo in the operating room and in vitro on aortic wall specimens. ${ }^{12-15}$ It is clear that the mechanical properties of the aorta deteriorate with enlargement. New imaging techniques promise to assess and convey aortic wall stress noninvasively. Four-dimensional imaging (including aortic blood flow velocity in addition to aortic dimensions in the standard 3 axes) appears especially promising. It must be borne in mind, however, that the algorithms for these imaging programs make important, and potentially misleading, assumptions, especially with regard to ambient blood pressure at the time of the examination and in regard to the "standard" elastic modulus of the aortic wall. ${ }^{16}$

\section{SUMMARY}

The important points regarding imaging and beyond that are the subject of this article are presented in Table 1. Assessment of the aorta and surgical decision making are likely to become more and more accurate and precise in the future as size is supplemented by genetics and by engineering measurements.

\section{References}

1. Coady MA, Rizzo JA, Hammond GL, Mandapati D, Darr U, Kopf GS, et al. What is the appropriate size criterion for resection of thoracic aortic aneurysms? J Thorac Cardiovasc Surg. 1997;113:476-91; discussion 489-91.

2. Coady MA, Rizzo JA, Hammond GL, Kopf GS, Elefteriades JA. Surgical intervention criteria for thoracic aortic aneurysms: a study of growth rates and complications. Ann Thorac Surg. 1999;67:1922-6; discussion 1953-8.

3. Davies RR, Goldstein LJ, Coady MA, Tittle SL, Rizzo JA, Kopf GS, et al. Yearly rupture or dissection rates for thoracic aortic aneurysms: simple prediction based on size. Ann Thorac Surg. 2002;73:17-27; discussion 27-8.

4. Elefteriades JA. Natural history of thoracic aortic aneurysms: indications for surgery, and surgical versus nonsurgical risks. Ann Thorac Surg. 2002;74: S1877-80; discussion S1892-8.

5. Davies RR, Gallo A, Coady MA, Tellides G, Botta DM, Burke B, et al. Novel measurement of relative aortic size predicts rupture of thoracic aortic aneurysms. Ann Thorac Surg. 2006;81:169-77. Erratum in: Ann Thorac Surg. 2007;84:2139.

6. Pape LA, Tsai TT, Isselbacher EM, Oh JK, O'gara PT, Evangelista A, et al; International Registry of Acute Aortic Dissection (IRAD) Investigators. Aortic diameter $\geq 5.5 \mathrm{~cm}$ is not a good predictor of type A aortic dissection: observations from the International Registry of Acute Aortic Dissection (IRAD) Circulation. 2007;116:1120-7.

7. Elefteriades JA, Farkas EA. Thoracic aortic aneurysm clinically pertinent controversies and uncertainties. J Am Coll Cardiol. 2010;55:841-57.

8. Elefteriades JA, Pomianowski P. Practical genetics of thoracic aortic aneurysm. Prog Cardiovasc Dis. 2013;56:57-67.

9. Pomianowski P, Elefteriades JA. The genetics and genomics of thoracic aortic disease. Ann Cardiothorac Surg. 2013;2:271-9.

10. Lemaire SA, McDonald ML, Guo DC, Russell L, Miller CC III, Johnson RJ, et al Genome-wide association study identifies a susceptibility locus for thoracic aortic aneurysms and aortic dissections spanning FBN1 at 15q21.1. Nat Genet 2011;43:996-1000.

11. Iakoubova OA, Tong CH, Rowland CM, Luke MM, Garcia VE, Catanese JJ, et al Genetic variants in FBN-1 and risk for thoracic aortic aneurysm and dissection. PLoS One. 2014;9:e91437.

12. Koullias G, Modak R, Tranquilli M, Korkolis DP, Barash P, Elefteriades JA Mechanical deterioration underlies malignant behavior of aneurysmal human ascending aorta. J Thorac Cardiovasc Surg. 2005;130:677-83.

13. Modak RK, Koullias GJ, Govindarajulu US, Tranquilli M, Barash PG, Elefteriades JA. Ascending aortic aneurysms: asymmetrical differences in aortic cross-sectional wall motion detected by epiaortic echocardiography. J Cardiothorac Vasc Anesth. 2010;24:776-9.

14. Martin C, Sun W, Pham T, Elefteriades J. Predictive biomechanical analysis of ascending aortic aneurysm rupture potential. Acta Biomater. 2013;9: 9392-400.

15. Martin C, Sun W, Primiano C, McKay R, Elefteriades J. Age-dependent ascending aorta mechanics assessed through multiphase CT. Ann Biomed Eng. 2013;41:2565-74.

16. Elefteriades J. Invited commentary. Ann Thorac Surg. 2013;95:598. 